\title{
Paper Surface Application with AKD-Heptane Solution Making Suitable For Biomedical Devices
}

\author{
Ahsen Ezel Bildik Dal* \\ Istanbul University, Forest Products Chemistry and Paper Technology Department, Turkey
}

Received: April 14, 2018; Published: April 30, 2018

*Corresponding author: Ahsen Ezel Bildik Dal, Istanbul University, Forest Products Chemistry and Paper Technology Department, Turkey

\begin{abstract}
Alkyl ketene dimer (AKD) has been used as a sizing agent all over the world to controlling penetration of liquids to the paper. In parallel with the technological development of biomedical devices, AKD-Heptane applications on the paper surface are becoming increasingly important. Conventional applications and technological methods need to be examined in order to reach suitable paper surface for all kind of device. This article fills that gap to measure paper properties after application both methods. Dipping method and printing method. In this paper, we used filter paper because of its pure structure. AKD to n-Heptane was $4 \%(v / v)$ on paper samples, then samples keep optimum heat condition for curing the AKD. The most important feature of AKD sizing is to improve the water repelling properties of paper; therefore, it was testedCobb ${ }_{60}{ }^{*}$ Then it was examined strength properties of these papers. Tensile test series and burst test indicated that printing method yield better results.
\end{abstract}

Keywords: AKD sizing

\section{Introduction}

AKD (Alkyl Ketene Dimer) has most spread using an internal sizing agent in the world, not only high efficiency to improve strength properties but also environmentally friendly agent. AKD production is greatly increased year by year and at the same time the price of AKD is decreasing. Previous studies applied AKD-Heptane solution with dipping method Seo et al. [1-4] for full hydrophobicity of paper samples. Also, printing method used by other researcher with ink jet printer for obtain patterned paper surface Kannangara et al. [5-7] Similar method used by W Shen and Liyun Guan as they dipped to the filter paper to Heptane-AKD solution Shen et al. [2]; Guan et al. [8]. From this model study, it could be suggested that AKD or hydrolyzed AKD attached and oriented on the cellulose surface by formation of the hydrogen bonding and ester bonding at the blending and heating stage, respectively Odberg, et al. [9]. Comparing these two commonly used methods it will offer an alternative option for situations where the paper need a certain degree of resistance rather than fully resistant to water.

Materials and Methods

\section{Akd Heptane Preparation and Application to the Filter Paper}

Analytical grade n-Heptane (Sigma-Aldrich) was used as the solvent of AKD wax samples. AKD wax samples supplied from
Diper Chemical Company. 4\%(v/v), AKD and n-Heptane was stirred ultrasound bath according to work of Jayawardane et al.(Jayawardane, Wei, \& McKelvie, 2014; Jayawardane , McKelvie, \& Kolev, 2012). Whatman filter paper was used as the base paper because of high purity of filter papers. One set of paper dipped to the solution. Other set of paper, printed with same solution used commercial Canon printer G3400. Filter paper samples were taken for 24 hin the hood then held for 5 minutes in a $105^{\circ} \mathrm{C}$ oven. All samples were tested in Istanbul University, Faculty of Forestry, Department of The Chemistry and Technology of Forestry Products SEKKA Laboratory after 24 hours in conditioning room according to ISO 287. Tensile (ISO 1924-2) and burst tests (ISO 2758) measured with Zwick Universal Test machine.

\section{Results and Discussion}

\section{Results of Physical Tests of Paper}

As application type of samples were untreated paper (None), dipping method (D.M), Printing method (P.M). Physical test results, basis weight changes and Cobb60 test results after application were given in figure 3.1.0ne of the feature of AKD is gained paper water resistance to the papers. Cobb $_{60}$ test results are show evidence of AKD bonding. According to results, even dipping method was give better results of imparting liquids, in printing method paper 
received the AKD Heptane solution more regularly using less active Heptane solution. Tensile index value shows us to papers internal bonding strength. Burst test gives us how strong bond fibers we have (Table 1).

Table 1: Physical test results, basis weight changes and Cobb $_{60}$ results of samples.

\begin{tabular}{|c|c|c|c|}
\hline Application & $\begin{array}{c}\text { Cobb }_{60} \text { Value } \\
\left(\mathrm{g} / \mathrm{m}^{2}\right)\end{array}$ & $\begin{array}{l}\text { Tensile Index } \\
\text { (N.m } / \mathrm{g} \text { ) }\end{array}$ & $\begin{array}{c}\text { Bursting Index } \\
\text { (kpa.m²/g) }^{2}\end{array}$ \\
\hline Base & - & 14,31 & 0.60 \\
\hline D.M. & 94.75 & 13.73 & 0.61 \\
\hline P.M. & 118.52 & 14.23 & 0.59 \\
\hline
\end{tabular}

\section{Conclusion}

AKD-Heptane treated paper sizing applications is a continuous mechanism that emits hydrophobic material onto cellulosic surfaces; hydrophobicity is strongly dependent on the amount of AKD in this kind of treatment. Since the same rates used in this study, the differences are due to the method of application itself. Present findings indicate that the dipping method could be used when an absolute liquid resistance is required. However, with the printing method, AKD Heptane solution was less consumed and obtained desired resistance to the paper against the liquid. The strength of the treated paper is slightly strained in the application of dipping method, yet the printing method treatment resulted in almost same results.

\section{References}

1. Seo WS, Cho NS, Ohga S (2008) Possibility of Hydrogen Bonding Between AKD and Cellulose Molecules During AKD Sizing Journal of the Faculty of Agriculture. Kyushu University 53(2): 405.

2. Shen W, Filonanko Y, Truong Y, Liesegang J (2000) Contact Angle Measurement and Surface Energetics of Sized and Unsized Paper. Colloids and Surfaces A Physicochemical and Engineering Aspects 173(1-3): 117-126.

3. Li X, Tian J, Nguyen T, Shen W (2008) Paper-Based Microfluidic Devices by Plasma. Anal Chem 80(23): 9131-9134.

4. Li X, Tian J, Garnier G, Shen W (2009) Fabrication of paper-based microfluidic sensors by printing. Colloids and Surfaces B: Biointerfaces 76(2): 565-569.

5. Kannangara D, Zhang H, Shen W (2005) Liquid-paper interactions during liquid drop impact and recoil on paper surfaces. Colloids and Surfaces A 280(1-3): 204-215.

6. Jayawardane MB, Wei S, McKelvie ID (2014) Microfluidic Paper-Based Analytical Device for the Determination of Nitrite and nitrate. Analytical Chemistry 86(15): 7274-7279.

7. Jayawardane MB, McKelvie ID, Kolev SD (2012) A paper-based device for measurement of reactive phosphate in water. Talanta 100(15): 454-460.

8. Guan L, Tian J, Cao R, Li M, Cai Z, et al. (2014) Barcode-Like paper sensor for smart phone diagnostics: An application of blood typing. An Analytical Chemistry 86(22): 11362-11367.

9. Odberg L, Lindstrom T, Liedberg B, Gustavsson J (1987) Evidence For Beta - Ketester Formation during The Sizing Of Paper With AlkylKetene Dimers. Tappi J 70(4): 135-139.

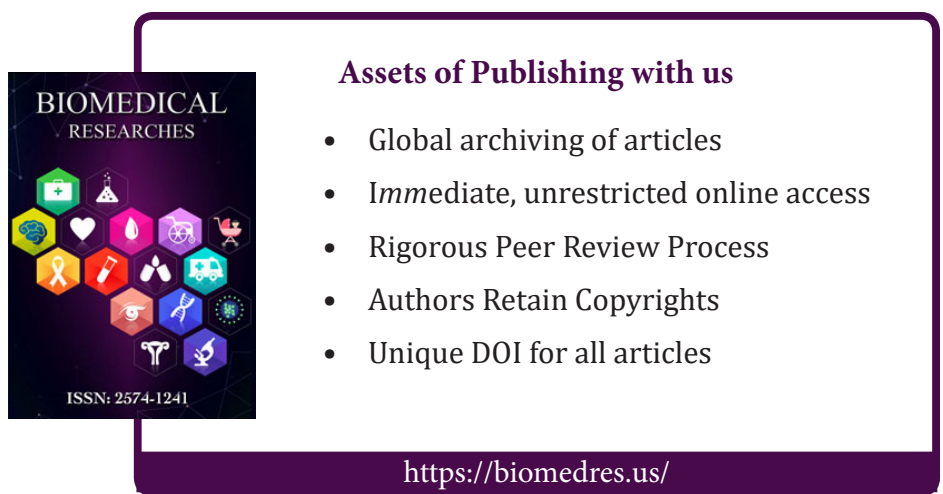

